\title{
CONSIDERAÇÕES SOBRE ALTERIDADE, EDUCAÇÃO E DEFICIÊNCIA
}

\author{
Carla K. Vasques \\ Universidade Federal do Rio Grande do Sul - UFRGS \\ Mônica Maria Farid Rahme \\ Universidade Federal de Minas Gerais - UFMG
}

\begin{abstract}
Resumo
O objetivo deste artigo é apresentar um conjunto de onze discussões distintas que conjugam a alteridade referindo direta ou indiretamente o campo das deficiências. Para tanto, refletimos sobre algumas das formas de acolher o outro e os efeitos éticos, epistemológicos e políticos dessas abordagens. Apontamos a importância da recusa desse outro - no caso, considerado com deficiência - como possuidor de uma essência prévia divorciada do contexto histórico, econômico e político que nos é constitutivo; a oposição a qualquer representação em negativo, capaz de produzir ou reproduzir processos de estigmatização; o encontro com a alteridade como irrupção capaz de interrogar nossa mesmice e desestabilizar nossos ordenamentos; e, por fim, o exercício da alteridade como promotor de justiça e responsabilidade social.
\end{abstract}

Palavras-chave: Educação. Deficiência. Alteridade.

\begin{abstract}
The purpose of this article is to present a set of eleven distinct discussions that combine otherness, directly or indirectly referring to the field of deficiencies. Therefore, we reflect on some of the ways to welcome the other and the ethical, epistemological and political effects of these approaches. We point out the importance of refusing this other - in this case, considered disabled - as possessing a previous essence divorced from the historical, economic and political context that constitutes us; the opposition to any negative representation, capable of producing or reproducing stigmatization processes; the encounter with otherness as an outbreak capable of interrogating our sameness and destabilizing our systems; and, finally, the exercise of otherness as a promoter of justice and social responsibility ${ }^{1}$.
\end{abstract}

Keywords: Education. Deficiency. Otherness. 


\section{Educação e alteridade}

A educação pressupõe o encontro com o outro, compreendendo esse encontro como uma forma de interlocução e intersubjetividade lastreados, sobretudo, pela linguagem. Desse modo, os atos educativos - como uma prática pedagógica, a escrita de um artigo, a pesquisa acadêmica ou outras atividades habituais dos trabalhadores da educação - sempre remetem ao problema do endereçamento, trazendo-o à tona: a quem uma pessoa dirige a sua palavra? E como ela o faz? Ademais, reconhecendo que o sentido da educação é inexoravelmente estimulado pelas vicissitudes desse encontro por meio de lastros linguísticos, qual será o lugar da palavra do outro, por exemplo, na organização curricular? Ou, então, na avaliação das aprendizagens? Sabemos da existência de metodologias que parecem ignorar o fundamental dessas ideias, esquecendo que o educar sempre implica, como numa carta, a transitividade entre remetentes e destinatários (Mautone, 2018). Mas sabemos também ser possível acolher essa presença outra, esse estranhamento, no exercício da apropriação crítica do patrimônio histórico-cultural humano. Fato é que ambas possibilidades, por desviarem radicalmente nos modos de acolhimento e cuidado sobre a questão do outro, produzem efeitos éticos, estéticos, epistemológicos, econômicos e políticos radicalmente distintos.

Mas, de que outro falamos? Iniciamos com a seguinte afirmação: o outro se diz de várias maneiras. $\mathrm{Na}$ acepção gramatical, refere-se a "algo ou alguém, cuja referência indefinida se encontra fora do âmbito do falante e do ouvinte, e que se contrapõe, implícita ou explicitamente, a algo ou alguém definido, conhecido" ${ }^{2}$. O outro é exterioridade, algo ou alguém que eu não sou, que difere de mim e, por isso, não efetivamos um plural. Ou, ao contrário, remete àquilo ou àquele próximo, legível a partir de convicções compartilhadas e até íntimas. Temos também um outro que nos habita, mesmo que o desconheçamos, por emergirmos como sujeitos a partir de um sistema de linguagem que nos antecede. $\mathrm{O}$ eu e o outro, nesta perspectiva, conformam complexas relações de intimidade e extimidade; de familiaridade e estranhamento; de proximidade e distanciamento mais ou menos conscientes, legíveis e capazes de enunciação. Compreendemo-nos, de toda a forma, como efeito da distância e da diferença em relação ao outro, encarnado, desde nossos primórdios, nos próximos cuidadores, nas identificações estabelecidas ao longo da vida e nas narrativas sóciohistóricas que conformam formas de pensar e viver.

A relação entre o eu e o outro, em meio aquilo que se opõe à identidade e se efetiva a partir da diferenciação é constitutiva, por sua vez, do que se convenciona chamar de alteridade. A psicanálise freudo-lacaniana, a teoria bakhtiniana e a genealogia foucaultiana, somente para citar alguns sistemas teóricos centrais na contemporaneidade, permitem pensar a alteridade no âmbito dos processos de subjetivação; nos dilemas da discursividade e do diálogo; na realização do reconhecimento e seus impasses; nas tensões e ambivalências relativas ao campo das políticas públicas e efetivação dos direitos humanos.

Sabemos que somente no interior de uma teoria é que podemos extrair todas as consequências do dito. Para discorrermos sobre a educação e seus outros, seria necessário iniciarmos pela problemática geral da alteridade para, num segundo tempo, circunscrevermos a temática que ora nos convoca. Do ponto de vista da psicanálise, por exemplo, poderíamos 
tomar a investigação realizada por Freud no domínio do fenômeno delineado pela palavra unheimlich, em seu ensaio $O$ inquietante, de 1919; ou situarmos a alteridade a partir dos registros do imaginário, do simbólico e do real, propostos por Lacan. Esses caminhos obrigariam uma pesquisa conceitual mais ampla, exigiriam articulações coerentes entre a teoria geral e o objeto de estudo e, por fim, ofertariam um horizonte compreensivo que, no universo limitado desta apresentação, não caberia promover. Não queremos produzir a ideia de um sentido primeiro - supostamente compartilhado entre os pesquisadores participantes desta seção temática - e, tampouco, afastar nosso argumento da sua especificidade. Justificamos, assim, nossa escolha por uma noção sincrética de alteridade: o outro aqui é aquele a quem o ato educativo se dirige considerando a educação como experiência de humanização, exercício de singularização, possibilidade de socialização e formação de um ethos comum (Charlot, 2000). É também aquele cuja presença incômoda interroga o Estado, as práticas de educação escolar, da docência, do currículo formal e do oculto (Arroyo, 2012).

A fim de delimitarmos nossa escrita, faz-se pertinente afirmar: os onze textos que ora se abrem conjugam a alteridade referindo direta ou indiretamente o campo das deficiências. Duas são as hipóteses comuns às abordagens: em torno da questão da alteridade se tece grande parte do trabalho do educador; o capacitismo permite questionar preconceitos, estigmas e naturalizações nas formas organizativas do trabalho pedagógico especializado e naquele identificado como comum/regular ${ }^{3}$. Diante de uma possível objeção quanto à amplitude e interesse desta seção temática amparamo-nos nas palavras de Amorin (2000, p. 28): "diferença no interior da identidade, pluralidade na unidade, o outro [considerado com deficiência] é ao mesmo tempo aquele que quero encontrar e aquele cuja impossibilidade de

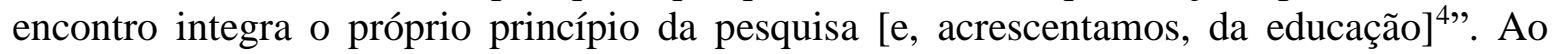
problematizarmos a deficiência, em nada afastamo-nos ou deixamos de responder àquilo que é do próprio centro normativo da educação e da resposta que se espera que ela dê à pluralidade de percursos e histórias de vida que todos e todas vivenciam.

\section{Abordagem alteritária da deficiência}

A população com deficiência apresenta taxas de pobreza mais elevadas, níveis de saúde e escolaridade piores e participação econômica reduzida, em decorrência, sobretudo, das barreiras de acesso aos serviços básicos: saúde, educação, emprego, transporte e informação. A situação agrava-se nas comunidades mais pobres, o que, em muitos casos, deságua em problemas de marginalização, exclusão e criminalidade (Madruga, 2016). As políticas públicas pretendem incidir neste estado de coisas, regulando e construindo outras formas de participação, acesso aos bens públicos e reconhecimento social.

A Convenção Internacional dos Direitos das Pessoas com Deficiência (Brasil, 2007) e a Lei Brasileira de Inclusão da Pessoa com Deficiência (Brasil, 2015), por exemplo, apresentam

a deficiência como uma limitação duradoura, agravada pela interação dos impedimentos naturais com as barreiras sociais, institucionais e ambientais, excluindo ou dificultando a 
participação do sujeito no meio social. A deficiência não é a expressão de um desvio relativo ao padrão biomédico, mas um conceito que denuncia a desigualdade imposta por ambientes com barreiras a um corpo com impedimentos (Diniz, Barbosa, Santos, 2010); capaz de promover justiça social pelas vias do cuidado como prática coletiva e da interdependência como substrato da sobrevivência humana (Kittay, 2011). Nesta perspectiva, os estudos sobre deficiência dialogam com diferentes áreas e temáticas como, por exemplo, raça e gênero (Morris, 1993).

As políticas educacionais inclusivas por sua vez, buscam redefinir discursos e práticas em consideração aos direitos humanos e às diretrizes inclusivas, uma vez que procuram promover mudanças na gestão, no currículo, na formação de professores, no acesso à escola e nos serviços de apoio aos alunos em situação de vulnerabilidade a fim de fazer operar os direitos à igualdade e à diferença ${ }^{5}$.

A despeito do valor moralmente inatacável da letra da lei, não foi dada a devida consequência à discussão sobre a alteridade no âmbito dos processos educacionais e formativos, seja em sua vertente especializada ou inclusiva. Pesquisas apontam a convivência entre pares como alvo de desconforto junto aos docentes e discentes; experiências escolares são reduzidas a práticas mecanicistas, restando ao "aluno especial" a marca da anormalidade e uma inserção na escola sob os auspícios da desconfiança, da normatização e do empobrecimento na relação com o outro (Rahme, 2014). Se a formação continuada pouco conjura outras formas de reconhecimento, nos cursos de licenciatura há um silêncio ruidoso e constrangedor no que se refere ao tema (Mônico, Morgado, Orlando, 2018); bem como, de um saber-fazer docente capaz de opor-se ao "inferno do mesmo" (Todorov, 2013).

Tomemos por exemplo as palavras de uma professora dos anos iniciais, identificada com o que intitula "tarefa incontestável de ensinar", proferidas durante uma formação continuada sobre a educação especial na perspectiva inclusiva: "Dessas crianças de cristal, o que se pode esperar? Aprenderão a fazer contas, a ler e a escrever? Como investir em alguém que parece não aprender? Como ser professora de alguém que não parece aluno? Melhor deixar para os especialistas..."6.

Gostaríamos de chamar atenção para a complexidade dessa fala, naquilo que comparece como alteridade extrema, capaz de ultrapassar a possibilidade de representação. O aluno com deficiência parece precipitar a queda de ideais de aprendizagem e de ensino e romper com os dispositivos de percepção em relação ao outro e a si. Neste desarvoramento, uma das primeiras consequências é a perda de credibilidade do fazer pedagógico e do próprio lugar de educadora, que se veem impossibilitados pela ausência de um interlocutor (aluno) lido como válido e valoroso. Diante das "crianças de cristal", ou seja, daquelas apartadas de humanidade, a primazia das decisões é delegada aos especialistas e aos conhecimentos considerados mais confiáveis e científicos, como aqueles da medicina e da psicologia.

Pesquisadoras como Moysés (2008) e Patto (2012) problematizam a presença da racionalidade médica na produção do fracasso escolar e do "ser deficiente". Em sintonia com estes estudos, percebemos também a preeminência capacitista e biomédica nas formas de conhecer em educação especial e naquela adjetivada como inclusiva. Esvaziados de seu caráter enunciativo, o comportamento, o gesto e o silêncio dos alunos com deficiência são 
enquadrados, depurados pelos questionários e escalas de medidas, a ponto de perderem o valor de palavra dirigida a alguém. O que era diálogo transforma-se em reação, perdendo-se, assim, a especificidade do humano (Vasques, 2015).

Acreditamos que uma outra abordagem não só é possível, como é eticamente irrecusável. Nesse sentido, tomamos como ponto de inflexão a fala de uma segunda professora, no contexto de formação referido anteriormente: "O autista da política não é o mesmo que chega em minha sala de aula. É preciso perder o autista para construir um aluno, uma professora e uma prática possível"7.

A ocorrência da alteridade parece habitar as margens entre o dado e o construído; entre o possível e o não possível de elaborar, representar e acolher. Fruto de uma operação de subtração, a perda do autista - entendida como esvaziamento do excesso de sentido advindo de enunciados normocêntricos e capacitistas - parece ser condição para singularizar encontros e construir um aluno, uma professora e uma prática possível.

A enunciação estrangeira - aquela do deficiente, da criança, do migrante e das mulheres, como os leitores acompanharão ao longo dos artigos - deixa marcas na prática educacional, na escrita do texto e na pesquisa, instaura uma crise, transformando-as e obrigando-as a falar e a fazer de outra maneira.

Se, como afirmamos, não comungamos uma hipótese geral acerca da alteridade, temos alguns preceitos, éticos e epistemológicos comuns:

1) A recusa do outro [no caso, considerado com deficiência] como possuidor de uma essência prévia divorciada do contexto histórico, econômico e político que nos é constitutivo;

2) a oposição a qualquer representação em negativo, capaz de produzir ou reproduzir processos de estigmatização;

3) o encontro com a alteridade como irrupção capaz de interrogar nossa mesmice e desestabilizar nossos ordenamentos;

4) o exercício da alteridade como promotor de justiça e responsabilidade social.

Essas questões colocam em causa especificidades do trabalho do educador e o ponto que permite construir, reconhecer e apostar no diálogo interdisciplinar diz respeito à educação como direito humano, à luta por uma educação pública, estatal, laica, de qualidade socialmente referenciada e inclusiva. Isso significa que é possível entendê-la como fenômeno coletivo que concerne a todos os sujeitos que experimentam o cotidiano escolar e que apostam na educação como um espaço de construção do laço social.

\section{Seção temática}

A seção temática Educação, alteridade e pacto democrático conjuga onze artigos, dos quais, sete são assinados por pesquisadores brasileiros (UFRGS, UFMG, UNICAMP, UFGD, UFPB, UNISUL e UFOP) e quatro por pesquisadores estrangeiros (Université Paris Descartes/França, Universidade Nacional Autónoma do México, Università degli Studi di 
Roma/Itália, Université de Laval, Université du Québec en Outaouais e Université du Québec à Trois-Rivières /Canadá).

Éric Plaisance, no artigo Alteridade, Modernidade e Democracia, contextualiza as relações entre o outrem e a alteridade, a unidade e a diversidade, no âmbito da educação democrática desde a perspectiva da filosofia moderna, bem como da antropologia e da sociologia contemporânea. Em diálogo com autores críticos, reafirma a alteridade como centro da ação educativa e sua aproximação com preceitos nomeados, recentemente, como inclusivos. A educação inclusiva, afirma, é capaz de modificar a relação habitual com o outro considerado diferente, pois o foco não se restringe somente às eventuais características "desviantes", mas se amplia para o ambiente, o currículo e outras tantas práticas pedagógicas e educacionais capazes de beneficiar a todos. Contudo, os impasses no acolhimento de crianças em situação de deficiência e também das migrantes são emblemáticos das dificuldades de efetivação desse projeto, por mais que seja moralmente inatacável. É nesse ponto que a temática da educação e seus outros afeta a realização de uma democracia alicerçada à ética e à alteridade.

Uma educação democrática que faça justiça à singularidade do outro depende crucialmente do diálogo. João José R. L. de Almeida, no artigo Reflexão sobre percepção de aspecto, aborda a temática da lógica, das regras, da visão de mundo e da normatividade do significado como forma de esclarecimento acerca de pressupostos influentes e potencialmente imiscuídos até mesmo em políticas educacionais inclusivas. A partir da filosofia de Wittgenstein, o autor propõe a investigação etnográfica dos problemas pedagógicos relativos à exclusão de seres humanos, da sua identificação como classe, que ao mesmo tempo cuide de não reintroduzir sub-repticiamente os próprios problemas que pretende solucionar. A pergunta pelo excluído, pelo diferente, começaria pela etnografia dos nossos conceitos e categorizações e do nosso correlativo sentimento de estranheza.

Afirmar a estranheza do objeto de pesquisa, ou de um campo investigativo, como própria condição desse objeto ou campo é o argumento proposto no artigo A pergunta esquecida: linguagem, alteridade e sujeito da educação especial, de Guilherme Mautone, André Lima e Carla Karnoppi Vasques. Os autores, também a partir da filosofia wittgensteiniana, sugerem que uma reorientação de certos pressupostos filosóficos subjacentes ao campo da educação especial é pertinente em função, sobretudo, dos efeitos de um reconhecimento lesivo oriundo das materialidades calcadas no biológico, ainda tão presentes neste campo. Em oposição, procuram reconduzir o debate ao pensar o aluno considerado com deficiência como sujeito que emprega a linguagem, elabora suas experiências e encontra-se inserido na forma de vida humana; extraindo, dessa gramática outra, importantes consequências políticas, éticas e epistemológicas.

A reconfiguração dos estudos sobre a deficiência, não mais pautado pela racionalidade médica, permite descrever a experiência da deficiência em termos políticos, econômicos, culturais e históricos. Patricia Brogna, no artigo Educación, disenso y políticas de discapacitación, problematiza essa temática a partir dos direitos humanos, aproximando a opressão social sofrida pelas pessoas consideradas com deficiência às formas de reconhecimento lesivo, estigmatização e exclusão sofridos, por exemplo, pelas mulheres e os 
negros. Em consonância com autores críticos, discute tantos os limites da educação, no que se refere aos padrões hegemônicos dos quais é produto e produtora, quanto sua potência para forjar leituras diversas sobre as formas de coabitar junto, de forma solidária, responsável e empática.

Para além das políticas da diversidade: interfaces da educação especial e da educação do campo, de Washington Cesar Shoiti Nozu e Marilda Moraes Garcia Bruno, estabelece aproximações entre áreas que sofrem descaso na seara das ações governamentais; são historicamente atingidas por práticas assistencialistas; têm seus público-alvo inferiorizados, estigmatizados, estereotipados e encontram-se em situação de invisibilidade; restando como vozes ausentes na cultura e no currículo escolar. O ensaio aborda, a partir de teorizações póscríticas, os dispositivos e os regimes de verdade da educação especial e da educação do campo para, então, problematizar as suas interfaces e propor a constituição de outras miradas.

Uma gramática sobre a questão da deficiência tecida a partir da alteridade e do ato democrático se efetiva no âmbito do escolar e do acesso aos processos educacionais formais. Por uma formação ética e estética de mulheres-professoras, Margareth Diniz divulga aspectos de uma pesquisa que teve por método a conversação, desde a perspectiva da psicanálise. Segundo a autora, é preciso interrogar processos padronizados de formação docente, de modo a produzir novos sentidos para questões subjetivas, políticas e sociais afeitas à diversidade e à diferença. Em diálogo com a noção de saber cunhada por Bernard Charlot, propõe que esse movimento, necessariamente, implica mal-estar e perceber-se como partícipe dos processos de inclusão e exclusão.

$\mathrm{O}$ trabalho colaborativo entre os professores da classe regular e do atendimento educacional especializado, dispositivo considerado central para os processos inclusivos de alunos com deficiência na escola comum, é o foco do trabalho de Libéria Neves e Mônica Rahme, intitulado Trabalho coletivo, sujeito e prática da conversação: uma contribuição a partir da perspectiva psicanalítica à educação especial. As autoras compartilham efeitos de uma pesquisa - desenvolvida a partir de três escolas pertencentes ao sistema de ensino estadual de Minas Gerais (MG) e ao sistema de ensino municipal da capital do estado, Belo Horizonte $(\mathrm{BH})$ - que teve também a conversação, como prática metodológica de orientação psicanalítica. Através da circulação da palavra, buscaram compreender elementos da subjetividade que constituem os sujeitos professores, os quais possam culminar em impasses na interlocução entre estes profissionais no espaço escolar; na capacidade de transmissão; e assim, consequentemente, no desenvolvimento dos alunos envolvidos.

A documentação pedagógica em uma experiência formativa na educação infantil: marcas de um percurso de encontro com o outro, de Onileda Matta Guimarães, Luciane Pandini Simiano e Simone Bicca Charczuk, tematiza os impasses e as possibilidades de escutar, registrar e valorar a voz do outro no âmbito das práticas pedagógicas. O argumento evoca a necessidade de construir dispositivos que permitam maior compreensão acerca da complexidade dos processos sociais, subjetivos e educacionais implicados no cotidiano das instituições de educação infantil.

Formação e acessibilidade: por uma escola e uma sociedade inclusivas, de Lucia De Anna e Alessio Covelli, discute a formação de professores inicial e continuada na Itália, 
articulando orientações de documentos formulados no país desde os anos de 1970 e recomendações da União Europeia, e dados relativos à prática da pesquisa. País pioneiro nos processos de integração e inclusão escolar de pessoas em situação de deficiência, os autores analisam a experiência italiana, focalizando aspectos facilitadores e dificultadores para a promoção da acessibilidade nos ambientes escolares. A colaboração entre a escola e os parceiros externos é indicada como um dos aspectos centrais e igualmente desafiador na construção de uma escola inclusiva.

O mapa itinerário para uma vida adulta: um programa inovador para a transição da escola-vida adulta, de Francine Julien-Gauthier, Julie Ruel e Colette Jourdan-Ionescu, apresenta e discute dados referentes à aplicação de um programa de apoio à transição escolavida adulta, destinada a jovens que apresentam deficiência intelectual, por educadores especializados de um centro de readaptação e de duas unidades escolares. O texto indica a importância do acompanhamento e da disponibilização de material acessível para os jovens que se encontram nesse momento de transição. Por outro lado, evidencia os limites da pesquisa na abordagem dos contextos familiares e comunitários, bem como os desafios presentes na articulação com os serviços de saúde, assistência social e espaços de trabalho. $\mathrm{O}$ texto se referencia no conceito de resiliência e em trabalhos sobre deficiência intelectual.

Finalizamos a seção temática com o artigo de José Tonezzi, O diferente na era digital, que focaliza a percepção do ser diferente em um contexto no qual as relações humanas são mediadas por equipamentos e aplicativos que nem sempre prescindem de uma exposição do corpo concreto. Diante da pergunta: qual o lugar de pessoas tidas como diferentes ou fora de padrão no mundo digital de hoje?, o autor traça um percurso instigante no qual interroga a dimensão estética, discute a prática da simulação e a emergência da bufonaria, tendo em vista que as mediações digitais permitem que os corpos pouco convencionais compareçam nesses dispositivos sem que suas supostas diferenças sejam observadas.

\section{Considerações finais}

Nas últimas décadas, os avanços em torno dos direitos humanos e da justiça social sofreram sucessivos ataques. Tomando o Brasil como exemplo, desde 2016, a lógica ultraneoliberal e conservadora ganha força e, numa sociedade violentamente desigual, racista e marcada pelos preconceitos contra pobres, negros, mulheres, população LGBT+ e pessoas com deficiência, princípios constitutivos do laço social são perigosamente desfeitos. Somadas a essa realidade e suas raízes históricas, a situação da pandemia pelo novo coronavírus aprofunda desigualdades e imprime restrições, para muitos, nunca experienciadas. Vivemos uma crise econômica, cultural e civilizatória que coloca em risco os direitos fundamentais e as expectativas sociais e normativas que lhes são subjacentes. Certamente, os efeitos desse momento se fazem e se farão presentes nas possibilidades de reconhecimento e acolhimento, sobretudo, daqueles mais frágeis.

A presente seção temática procura disputar sentidos e promover diálogo público. Ao tematizar a alteridade, a educação e a deficiência colocamo-nos a serviço da democracia, dos 
direitos humanos e na luta contra o desamparo e o preconceito; de modo a perfazer os mais caros ideais de uma ciência comprometida com a ética do cuidado, do bem comum e do viver juntos.

Desejamos uma excelente leitura.

\section{Notas}

1. Agradecimento especial ao trabalho de tradução de Mônica Terezinha de Souza

2. OUTRO. In: DICIO, Dicionário Online de Português. Porto: 7Graus, 2020. Disponível em: <https://www.dicio.com.br/outro/>.

3. Ableism, derivado do verbo em inglês able - ser capaz de., é um termo sem tradução na língua portuguesa. Diferentes pesquisadores adotam capacitismo como expressão correlata, a fim de indicar uma forma peculiar de opressão contra as pessoas com deficiência derivada da "ideologia da normalidade sobre os corpos com impedimentos" (Diniz; Barbosa; Santos, 2010) ou do suposto afastamento da capacidade, da habilidade e da aptidão tidas como normais (Mello, 2016).

4. Os acréscimos são nossos.

5. A agenda política do atual governo brasileiro coloca em suspensão esse movimento, haja vista, por exemplo, a recondução anunciada pelo Decreto N. ${ }^{\circ}$ 10.502, de 30 de setembro de 2020, que institui a Política Nacional de Educação Especial: equitativa, inclusiva e com aprendizado ao longo da vida.

6. Ver Vasques, Moschen (2017).

7. Vasques, Moschen (2017).

\section{Referências}

AMORIM, Marília. O pesquisador e seu outro: Bakhtin nas Ciências Humanas. São Paulo: Musa, 2004.

ARROYO, Miguel Gonzalez. Outros sujeitos, outras pedagogias. Petrópolis: Vozes, 2012.

BRASIL. Decreto n. ${ }^{\circ}$ 6.949, de 25 de agosto de 2009. Dispõe sobre a Convenção Internacional sobre os Direitos das Pessoas com Deficiência e seu Protocolo Facultativo, assinados em Nova York, em 30 de março de 2007.

BRASIL. Lei n ${ }^{\circ}$ 13.146, de 6 de julho de 2015. Institui a Lei Brasileira de Inclusão da Pessoa com Deficiência (Estatuto da Pessoa com Deficiência). Presidência da República - Casa Civil - Subchefia para Assuntos Jurídicos. Brasília (DF), 2015.

CHARLOT, Bernard. Da relação com o saber: elementos para uma teoria. Porto Alegre: Artes Médicas Sul, 2000.

DINIZ, Débora; BARBOSA, Lívia; SANTOS, Wederson Rufino dos. Deficiência, direitos humanos e justiça. São Paulo, Sur - Revista Internacional de Direitos Humanos, n. 11, p. 6578, 2010.

KITTAY, Eva. The ethics of care, dependence, and disability. A internacional journal of jurisprucence and philosophy of law. USA, v. 24, n. 1, p. 49-58, 2011.

MADRUGA, Sidney. Pessoas com Deficiência e Direitos Humanos: ótica da diferença e ações afirmativas. 2. ed. São Paulo: Saraiva, 2016

MAUTONE, Guilherme. O que nos diz uma carta? Aproximações ensaísticas para uma filosofia epistolar. 2018. Disponível em: https://www.academia.edu/42104146/O_que_nos_diz_uma_carta_Aproxima\%C3\% A7\%C3\%B5es_ensa\%C3\%ADsticas_para_uma_filosofia_epistolar_por_Guilherme_Mautone\&gt.

Acessado em 27 janeiro de 2020.

MELLO, Anahi Guedes de. Deficiência, incapacidade e vulnerabilidade: do capacitismo ou a preeminência 
capacitista e biomédica do Comitê de Ética em Pesquisa da UFSC. Ciênc. saúde coletiva, Rio de Janeiro, v. 21, n. 10, p. 3265-3276, 2016.

MÔNICO, P. A; MORGADO, L.A.; ORLANDO, R.M. Formação inicial de professores na perspectiva inclusiva: levantamento de produções. Psicol. Esc. Educ., Maringá, v. 22, p. 41-48, 2018.

MORRIS, Jeanny. Feminism and disability. Feminist Review, n. 43, p. 55-67, 1993.

MOYSÉS, Maria Aparecida. A institucionalização invisível: crianças que não aprendem na escola. Campinas: Mercado das Letras, 2008.

PATTO, Maria Helena. A produção do fracasso escolar: histórias de submissão e rebeldia. São Paulo: Casa do Psicólogo, 2012.

RAHME, Mônica M. F. Laço Social e Educação: um estudo sobre os efeitos do encontro com o outro no contexto escolar. Belo Horizonte: Fino Traço, 2014.

VASQUES, Carla Karnoppi. Formas de conhecer em educação especial: o diagnóstico como escudo e lista. Revista de Educação PUC-Campinas, [S.1.], v. 20, n. 1, p. 51-59, 2015.

VASQUES, Carla K.; MOSCHEN, Simone Zanon (Org.). Psicanálise, educação especial e formação de professores: construções em Rasuras. Porto Alegre: UFRGS, 2017.

\section{Correspondência:}

Carla K. Vasques: Doutora em Educação pela UFRGS. Professora do PPGEDU/UFRGS. É integrante da Rede Internacional de Pesquisa em Psicanálise, Educação e Política (RIPPEP). Coordenadora do Núcleo de Pesquisa em Psicanálise, Educação e Cultura - NUPPEC.

ORCID: 0000-0002-3284-8749.

E-mail: k.recuero@gmail.com.

Mônica Maria Farid Rahme: Doutora em educação pela Universidade de São Paulo. Atua no ensino, pesquisa e extensão na Faculdade de Educação da UFMG. É integrante da Rede Internacional de Pesquisa em Psicanálise, Educação e Política (RIPPEP), do Laboratório de Estudos e Pesquisas Psicanalíticas e Educacionais (LEPSIMinas) e do Grupo de Trabalho de Psicanálise e Educação da Anpepp.

ORCID: 0000-0003-2123-2989.

E-mail: monicarahme@ufmg.br

Texto publicado em Currículo sem Fronteiras com autorização das autoras. 